Open Access

\title{
The business model prism: managing and innovating business models of arts and cultural organisations
}

\author{
Giovanni Schiuma* and Antonio Lerro
}

\author{
* Correspondence: \\ giovanni.schiuma@unibas.it; \\ schiumagio@gmail.com \\ Department of Mathematics, \\ Computer Sciences and Economics, \\ University of Basilicata, Viale \\ dell'Ateneo Lucano, Potenza, Italy
}

\begin{abstract}
Purpose: This paper introduces and analyses the Business Model Prism (BMP) for the arts and cultural organizations as multidimensional framework to map the "as is" structure and the logic of their business model as well as to drive the design of innovation initiatives, i.e. the "as should be" business model. The framework can be used both for descriptive and normative purposes and comprises seven facets organized and represented with a tri-dimensional prism which defines the key business components of arts and cultural organisations.
\end{abstract}

Design/methodology/approach: The research design and methodology are based on a literature review on the themes of business models and business models innovation with a focus on the characteristics and features of the arts and cultural organisations. This paper has a conceptual nature and it is based on a literature review. This includes also a desk research investigation of some key examples of arts and cultural organisations that have adopted innovations to transform the way how they work and deliver value to audience. The development of the novel framework builds the foundation for applying operatively and testing it in arts and cultural organisations and supports them in mapping and transforming effectively their business model.

Originality/value: Traditionally great attention the studies on business model innovation have been focused on businesses and public organisations, while rather limited attention has been paid to the investigation of how arts and cultural organisations can develop and manage their business models. Most of the attempts in this direction are aimed at contextualising, in the cultural sector, frameworks that have been devised for the business sector. Although acknowledging the relevance of these contributions, they present weaknesses related to the capacity to take into account the specific characteristics and features of the arts and cultural organisations. The originality and the value of this paper resides, then, in the attempt to fill this gap, providing a new and industry-specific framework able to effectively support the management and the innovation of the business models in the arts and cultural sector.

(Continued on next page) 
(Continued from previous page)

Practical implications: The proposed framework can support arts and cultural managers to understand the key dimensions characterising the business model of their organizations. In addition, it provides guidelines to map and design managerial initiatives to develop and transform the business model of arts and cultural organisations.

Keywords: Business model innovation, Arts and cultural Organisations, The business model prism, Arts and cultural management

\section{Introduction}

Arts, creative and culture-driven industries and organizations are widely recognized as new key-players in the current scenarios for their economic and social role as well as for the relevant potential to lead further development and innovation in other industries (Schiuma, 2011; United Nations, 2008). However, the political and socio-economic changes of the last years have determined that public support for arts and culture have generally decreased dramatically with reduction of subsidies towards the arts and cultural organizations (Kea, 2006). This has increasingly encouraged arts and cultural institutions to explore new ways of managing and funding their artistic and cultural programs (Nesta, 2014).

In this scenario, the academic and management debate has largely argued about the relevance to enhance the cultural sector organisations' innovation capacity so that they can be more economic sustainable, they can become less dependent from public funding as well as capable of generating more significant and accountable impact for society at large (Arts Council England, 2011). In particular, arts and cultural organisations are increasingly called to explore the elaboration and the adoption of new business models (Munoz-Seca, 2011; Munoz-Seca and Riverola, 2010; TEH, 2015).

The business model innovation is actually one the main interests for most industrial sectors and organisations. However, arts and cultural organisations present some peculiarities that make the analysis of business model management and innovation very idiosyncratic. The specific characteristics of the sector makes very problematic the simple application of those framework that have been devised and applied traditionally in the business and public organisations. Despite a great "fad" in the current debate about how to analyse, shape and renew the orientations and the ways of doing in the arts and cultural sector, there is a general lack of data around this sector and specifically about the characteristics distinguishing the business models of the arts and cultural organisations as well as of the practices and the results of business model innovation. This is further complicated by the evidences that even within the arts and cultural organisations it is possible to find great differences in missions and aims, orientation to the market and to the entrepreneurial approach, including ways of managing activities, resources, and stakeholders' relationships (Hume et al., 2006; Munoz-Seca and Riverola, 2008; TEH, 2015).

In order to fill these gaps, this paper proposes a new framework aimed to support a better management and innovation of the business models of arts and cultural organisations. In particular, the Business Model Prism (BMP) is introduced and discussed as a multidimensional model to be used both for descriptive and normative purposes. It 
allows to analyse the "as is" structure and the logic of the business model of the arts and cultural organisation as well as to drive the design of innovation initiatives, i.e. the "as should be" business model. The framework comprises seven facets organized graphically around a tri-dimensional prism.

The paper is organized as follows. The second section briefly introduces the notions of business model and business model innovation. The third section discusses the strategic relevance of the business model management and innovation for the arts and cultural organisations. The fourth section introduces the Business Model Prism as a tri-dimensional model aimed to support both the analysis and the transformation of the business models of the arts and cultural organizations and presents the main managerial issues and questions it tries to answer.

\section{Background}

The arts, creative and cultural sector, with their relationships to be activated with the social entrepreneurship, the tourism and hospitality industries, and even with the agri-food business, are increasingly acknowledged as a new engine for stimulating and enhancing growth with an impact on well-being, new employment and society at large (United Nations, 2008).

Despite the relevance that arts and cultural organisations can potentially play to sustain local and global wealth creation dynamics, currently they are facing critical challenges for their growth and even survival. In particular, as a result of political and economic changes of the last decade, the allocation of financial resources, public supports and funds for arts and culture have decreased consistently. These radical changes are forcing arts and cultural organisations to identify new ways of managing and funding their activities (Cunningham, 2002; TEH, 2015; Thorsby, 2008; IDEA Consult, 2013). In this scenario, a relevant theme in the scientific and practitioners' debate is the challenge of enhancing the innovation capacity of arts and cultural organisations in order to improve their sustainability and ability to generate impact for society. For this reason a set of priorities have been identified and highlighted for the arts and cultural organisations, such as the development of new mindsets (Zomerdijk and Voss, 2010), the search of new funding and financing models (Nesta, 2014), the acquisition of managerial and business skills (Helmig et al., 2004), the understanding about how to exploit the digital transformation (Nesta, 2015), the creation of new forms of partnership (Ostrower, 2004; Schiuma, 2011; Schiuma and Lerro, 2013; Smagina and Lindemanis, 2012), the adoption of strategies for audience development (Bollo, 2013).

The above priorities point out that arts and cultural organisations need to undertake a development journey towards the capacity of managing and innovating the ways how they operate, interact with stakeholders, define their value objectives, acquire and deploy resources, and support economically their artistic, cultural and social programmes. This means to understand how to manage and innovate their business models.

\section{The notion of business model (BM)}

A working definition of Business Model (BM) is: "the synthesis and the integration of all the strategic, organizational, managerial and economic components that any organizations - explicitly or implicitly - design, implement, manage, assess and eventually 
change and radically transform to guarantee uniqueness, performance, value creation and sustainability" (Magretta, 2002; Osterwalder and Pigneur, 2010; Spieth et al., 2014; Teece, 2010; Timmers, 1998).

Historically, the BM notion has emerged in the late 1990s, with a particular attention to the Information and Communication Technologies and e-business companies (Afuah and Tucci, 2003; Wirtz, 2001). Since then, the notion has attracted a growing interest both in scientific and managerial debate (Casadesus-Masanell and Zhou, 2013; Enev and Liao, 2014; Frankenberger et al., 2013; Girotra and Netessine, 2014; Zott et al., 2011). Currently, it is possible to state that, from a scientific point of view, the notion of BM has become a mainstream topic in different research streams (Wirtz et al., 2016). And in the extant academic literature, the concept of business model has been conceptualized in accordance with different focuses and perspectives (Amit and Zott, 2001; Chesbrough and Rosenbloom, 2002; Magretta, 2002; Casadesus-Masanell and Ricart, 2007). Wirtz et al. (2016) group them according to four main foci: innovation; change and evolution; performance and controlling; and design. Moreover, Wirtz (2010) identifies three basic theoretical approaches to the interpretation of BM as follows: the Information Technology-oriented view (Afuah and Tucci, 2003; Hedman and Kallig, 2002; Timmers, 1998; Wirtz, 2000); the Organization-theory oriented standpoint (Linder and Cantrell, 2000; Tikkanen et al., 2005) and the Strategy-oriented approach (Magretta, 2002; Teece, 2010; Zott and Amit, 2008).

A number of definitions about business model have been provided in the academic literature. Among them, Osterwalder and Pigneur (2010, p. 14) state that "a business model describes the rationale of how an organization creates, delivers and capture value". Casadesus-Masanell and Zhu (2013, p. 465) argue that "the business model can be defined as a unit of analysis to describe how the business of a firm works". Zott et al. (2011, p. 1020) sustain that business model describes "a logic story explaining who the firms' customers are, what they value, and how firms will make money providing them that value". Other scholars, such as George and Bock (2011), Downing, (2005), Markides, (2013), Cohen and Winn (2007), instead, provide a different perspective. In particular, on the basis of a review of prior research, they provide an interpretation of the business model according to an entrepreneurial lens. So, they see business model as a form of entrepreneurial opportunity creation, implicitly or explicitly initiated by market imperfections.

However, George and Bock (2011, p. 83) underline that "while the term "business model" has gained widespread use in the practice community, the academic literature on this topic is fragmented and confounded by inconsistent definitions and construct boundaries". Moreover, the studies on business model have not yet reached a common opinion about which components exactly build up a business model (Spieth et al., 2014). It is revealed a gap to clearly distinguish the business model from other managerial constructs such as, for example, strategy, organizational design, revenue models, and operations management (DaSilva and Trkman, 2014).

\section{The notion of business model innovation (BMI)}

The analysis of a business model is aimed at providing managers with an understanding of the key components characterising the working mechanisms and the value creation 
dynamics of an organisation, in order to propose adjustments, improvements or transformations. The definition of a new business model or the transformation of an existing one denote a process of business model innovation.

To define the notion of business model innovation, it seems relevant to begin with the contribution provided by Wirtz (2011, p. 72) who states that "BM management constitutes an instrument for the control of a company and comprises all target-oriented activities within the scope of design, implementation, modification and adaptation as well as the control of a business model in order to realize the overriding goal of generating and securing competitive advantage." (....) It "consists essentially in five macroprocesses: the design of the business model, the implementation of the BM, the operation of the BM, the adaptation and the modification of the BM and finally the controlling of the $B M$ ". This view highlights that while business model management is traditionally concerned with firm-level value creation and capture, Business Model Innovation (BMI) poses in addition questions about novelty in customer value proposition and about the reframe and structural reconfiguration of firms (Schneider and Spieth, 2013). Consistently, the management literature has developed alternative interpretations of business model innovation such as: "the discovery of a fundamentally different business model in an existing business" (Markides, 2006, p. 20) or as "the search for new business logics of the firm and new ways to create and capture value for its stakeholders" (Casadesus-Masanell and Zhu, 2013, p. 464).

In fact, innovation is incorporated into a business model when two or more of its elements are reinvented. This can result in delivering value in a new way, to go beyond single-function strategies and to change use of technologies (Frankenberger et al., 2013). Accordingly, it is important to distinguish business model innovation from product, service or technological innovation (Baden-Fuller and Haefliger, 2013). Managers that confuse the latter for the former risk underestimating the requirements for a successful transformation of a business model. The main scope of the business model innovation is to identify approaches and methodologies to support change management as well as daily practices to better deliver sustainable performance. Therefore, business model innovation goes beyond product and/or process innovation and continuous business performance improvement, and aims to understand how to transform the way organisations operate and create value (Enev and Liao, 2014).

Business model innovation is nowadays considered particularly valuable as a way to face instability. Indeed, it can provide companies a way to break out of intense competition. Through business model innovation companies can define new routes for sustainability and competitiveness. This means that organisations by analysing, managing and innovating business model can define their role and capacity for wealth creation and then identify the nature and scope of their value creation dynamics.

\section{The role of business model innovation for the arts and cultural organizations}

Multinationals and relevant corporations operating in the manufacturing or in the $e$ business context have been traditionally the object of investigation of the studies about the business models. In contrast, there was a notable lack of attention to the practices of small and medium-sized enterprises. In particular, there is still a significant missing of attention towards the organisations operating in the arts, creative and cultural industries (Munoz-Seca, 2011). 
However, in the recent years, there has been a growing attention to the arts, creative and cultural sector. Different reasons contributed to this growing interest. They can be divided into two main categories: on the one hand, arts and cultural organisations are challenged to understand how they can achieve financial viability, without compromising their mission and/or not-for-profit values. On the other hand, the progressive evolution of the political, economic and socio-cultural scenarios put the arts and cultural organisations as players of cultural activities as well as providers of social innovation, of cultural and creative services, and catalysts for change for organisations operating in other traditional sectors (TEH, 2015; Schiuma \& Lerro, 2014).

Although business modelling is recognized as being fundamental to arts, creative and cultural organisations' success, the approaches, the techniques and the tools for elaborating, implementing and managing specific and tailor-made business models in arts and cultural sector are still crude and often inconsistent (Hume et al., 2006; Munoz-Seca, 2011; Munoz-Seca and Riverola, 2010, 2008; Zomerdijk and Voss, 2010).

One of the main obstacles to business model innovation in the cultural sector is the lack and/or misunderstanding of the language used in the sector. Indeed, many nonprofits, government agencies, social enterprises, NGOs and cultural and arts organisations consistently proclaim that they are not businesses, and therefore business rules do not apply to them and accordingly they state that they do not really have a "business model". But, how underlined by Saul Kaplan (2011, p. 2) in his HBR article 'Business Models Aren't Just for Business': "if an organisation has a viable way to create, deliver, and capture value, it has a business model. It does not matter whether an organization is in the public or private sector. It does not matter if it is a non-profit or a for-profit enterprise. All organisations have a business model. Non-profit corporations may not be providing a financial return to investors or owners, but they still capture value to finance activities with contributions, grants, and service revenue. Social enterprises may be mission-driven, focused on delivering social impact versus a financial return on investment, but they still need a sustainable model to scale. (....). The idea that business models are just for business is just wrong. Any organisation that wants to be relevant, to deliver value at scale, and to sustain itself must clearly articulate and evolve its business model. (...). It may be, however, that the model is implicit rather than explicit".

Nowadays, an increasing number of creative, cultural and arts organisations are recognizing the importance to better understand manage and change their business model in order to make their value creation capacity more sustainable and impactful. The relevance of understanding and managing business models is recognized as one of the main challenges facing creative, cultural and arts organisations. In particular, great attention is paid on the identification of how to renew their capacity of existing working mechanisms as well as to enable them to effectively use and exploit technologies supporting digitalization processes. Cultural organisations are challenged to develop a more sustainable strategic and operational audience development, financial viability, resource and operations management, with the aim to enhance their value creation capacity as cultural agents in society.

This new strategic and operative perspectives need to be effectively understood and integrated with the current mindset of the arts and cultural organisations, considering that they are generally reluctant to consider themselves as business organisations or as organisations doing some form of business; and instead they see themselves as 
organisations primarily focused on the social issues. Accordingly, particular relevant are the insights provided by Ingrid Burkett in her publication "Using the Business Model Canvas for Social Enterprise Design (available at: https://mbs.edu.getmedia/ 91cc0d01-3641-4844-b34c-7aee15c8edaf/Business-Model-for-SE-Design-Burkett.pdf); she states that balancing a social or cultural mission "does not mean that a viable business model cannot be developed" (p. 6) - "It is just that we need to recognize that (cultural) organisations have business models that can be a little different from an ordinary business (...) and to build into the traditional modelling a clear picture of the social objectives (or the mission) of the organisation, in addition to all the dimensions of the actual business" (p. 7).

In order to address the business model innovation challenges of the arts and cultural organisations, different frameworks providing useful guidelines to design, manage and transform business models have been proposed more recently in the academic literature and practitioner-based publications. Combining these main contributions with the characteristics of the arts and cultural organisations a framework identifying the key specific dimensions of the business model distinguishing the cultural industry is proposed.

\section{The business model prism}

\section{Research design, data and methods}

The research design has been primirily based on a systematic review of the literature about business model innovation in the cultural sector. Electronic search tools, keywords and search strings to identify relevant research constructs were used. The use of keywords is the most important building block of a systematic search. The underlying assumptions are that keywords capture the field under study and the electronic databases can identify the studies based on those keywords. Search strings are comprised of combinations of keywords. Thus, the success of the systematic literature review depends greatly on the choice of keywords and search strings used to conduct the search. The choice of the keywords and strings for the research constructs were defined on the basis of a consultation of a number of arts and cultural organsations as well as of a delphi group of experts in the field.

In addtion the various dimensions and notions identified in the literature and related to "Business Model" and "Business Model Innovation" were identified and investigated by means of a review of the key outlets for scholarly research in the economic, strategic management and social science field (see MacMillan and Stern, 1987; MacMillan, 1989; 1991; 1994). Then, the collected research materials have been downloaded and imported into a reference manager database. Each research material was analysed. The results of this analysis were stored into the reference manager database in accordance with specific workform. In deciding on the electronic bibliographic databases to be used in the study, the search string were inputted into the most widely used web search engine, e.g. Google and Google Scholar. Moreover, a detailed identification and review of the most important existing strategic and managerial frameworks has been designed and implemented. In particular, the following key frameworks have been analysed: the Strategy Map and the Success Map (Kaplan and Norton, 2000), the Balanced Scorecards (Kaplan and Norton, 1996), the Performance Prism (Neely, 2002; Neely et al., 2001, 2002; Neely \& 
Adams, 2001), the Business Model CANVAS (Osterwalder and Pigneur, 2010), the Business Model Cube (Lindgren and Rasmussen, 2012), the Lean Canvas (Maurya, 2015), the Business Model Innovation Matrix (Girotra and Netessine, 2013, 2014).

The analysis of the research constructs gained by the systematic literature review based on key-words and strings and of the different strategic and managerial frameworks has been then integrated with the results of a specific desk-research on a selected and relevant sample of world-wide arts and cultural organisations. This has been further integrated by the main insights collected from direct contacts and interviews with a selected sample of European arts and cultural organisations.

\section{Research insights}

The results of the investigation have provided the informative base for proposing a novel framework to interpret the business model of arts and cultural organisations. The Business Model Prism (BMP) is, then, proposed as a multidimensional framework to be used both for descriptive and normative purposes to understand and transform the business models of the arts and cultural organisations. It is presented as a tridimensional prism comprising seven facets (Fig. 1). The top and bottom facets of the prim denote the Social and Cultural Value \& Impact, and the Funding and Financial Resilience, respectively. The other five facets of the prism correspond to the other key dimensions characterizing a business model of the arts and cultural organisations: Stakeholders, Strategies, Processes, Organizational Resources, and Partnerships.

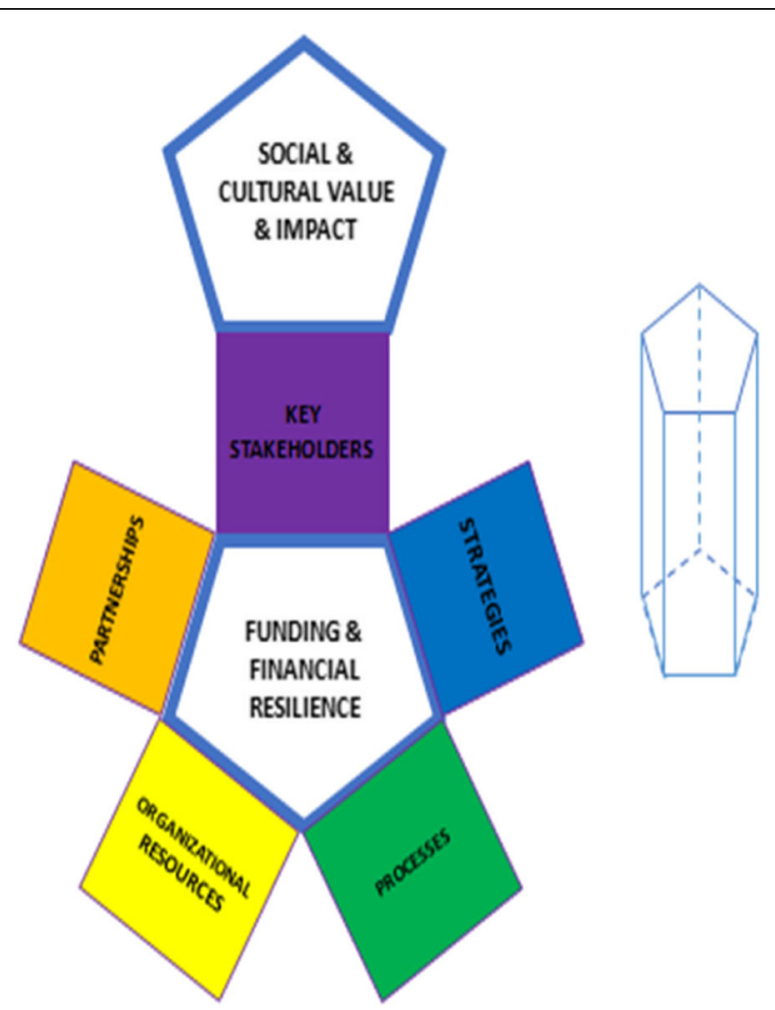

Fig. 1 The Business Model Prism for ACOs 
The Business Model Prism can support the identification and the mapping of the peculiarities of the business models of the arts and cultural organisations. It takes into account the specific features of the value creation focus and the operation mechanisms of such organisations. It allows to analyse the "as is" structure and logic of an arts and cultural organisation business model as well as to drive the design of innovation initiatives, i.e. the "as should be" business model. The seven distinct but inter-linked perspectives provide an ideal lens to understand the business model of an arts and cultural organization starting from addressing the following key questions:

- Social and Cultural Value \& Impact - Why do we exist? What impact do we want to have? Which values do we want to propose and offer? What are our mission and vision?

- Stakeholders - Who are our key-stakeholders? What are their wants, needs, expectations and dreams?

- Strategies - What are we doing to satisfy our stakeholders and deliver value for them? What are the main products and services we are doing? What is our legal structure? How is currently our organizational structure?

- Processes - What are our existing processes? How do we manage our projects and programmes? What are the characteristics of our productions? How do we generate and sustain demand? How do we do Research \& Development (R\&D)?

- Organizational Resources - What resources do we need to put in place, exploit and enhance to operate our processes?

- Partnerships - What partnerships do we need to build and enhance to implement our strategy and guarantee social and cultural values and impact?

- Funding and Financial Resilience - What are our current costs and incomes? What is our financial status?

The above key questions define the main issues to be addressed and managed to supporting the development of the fundamental theoretical pillars distinguishing the business model of an arts/culture organisation and provide a first step to understand the hypothesis grounding the "how", "why", "what" and "how much" of the working mechanisms, mission and vision of the investigated organisation. The above questions are then cascaded down for each perspective of the prism exploring further in detail the sub-dimensions components of the prism. Figure 2 illustrates the further subcomponents of the Business Model Prism.

The Business Model Prism reflects and applies a set of internal working mechanisms: the basic assumption of the business model prism application is that those arts and cultural organisations aiming to be sustainable and impactful in the long term must have a clear picture of their value creation dynamics. For this reason, they need, firstly, clearly define what value and impact they are going to deliver and for who, and consequently they have to define mission, visions and strategies. The key stakeholders have to be identified, and, in relation to them, the value propositions have to be defined. Then, the analysis of the processes allows clarifying the activities that have to be put in place in order to achieve the targeted strategic objectives for value creation. This has to be complemented with an understanding of the organisational resources available and needed. The key partners have to be identified and the relevance of the relational capital 


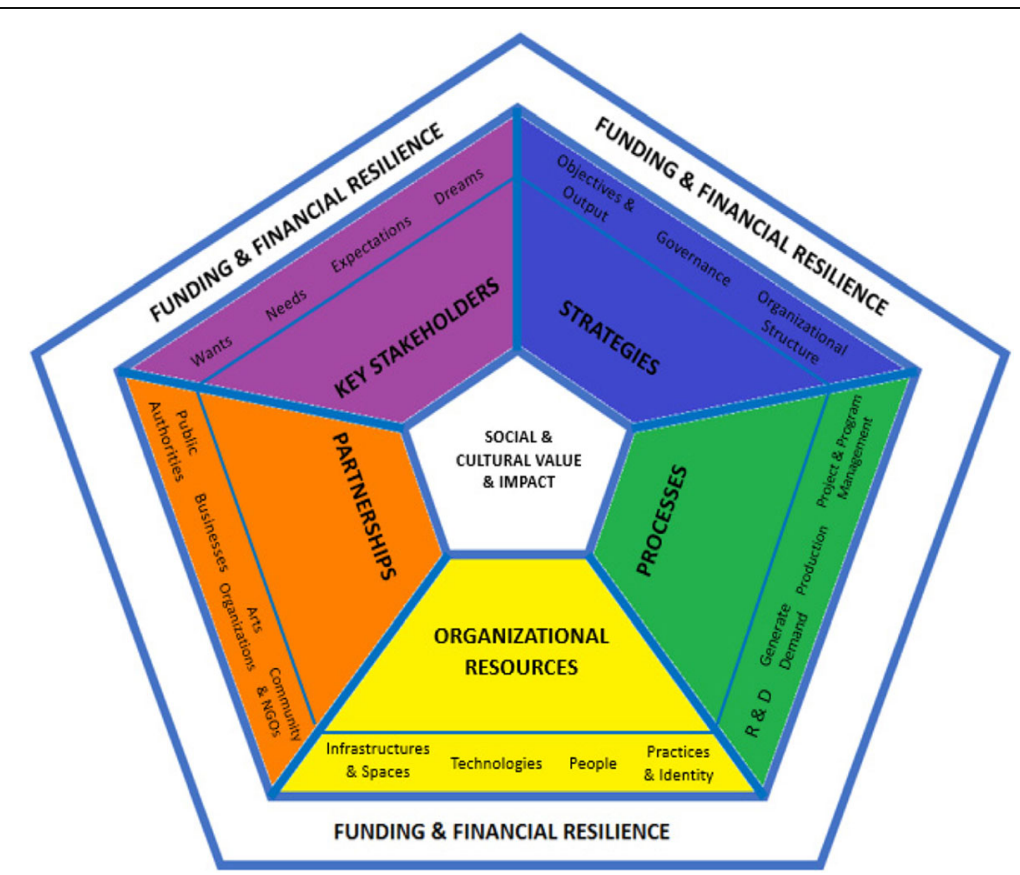

Fig. 2 The Business Model Prism and related sub-components

connected to such partnerships has to be defined. Finally, the business model analysis involves an understanding of the funding and financial resilience representing the economic and financial viability of the organisation. Figure 3 illustrates the stages through which to implement the framework in order to analyse a business model.

\section{Conclusions}

The debate in policy, scientific and managerial circles have recently started to consider arts and cultural organisations as potential and relevant players in the paths of

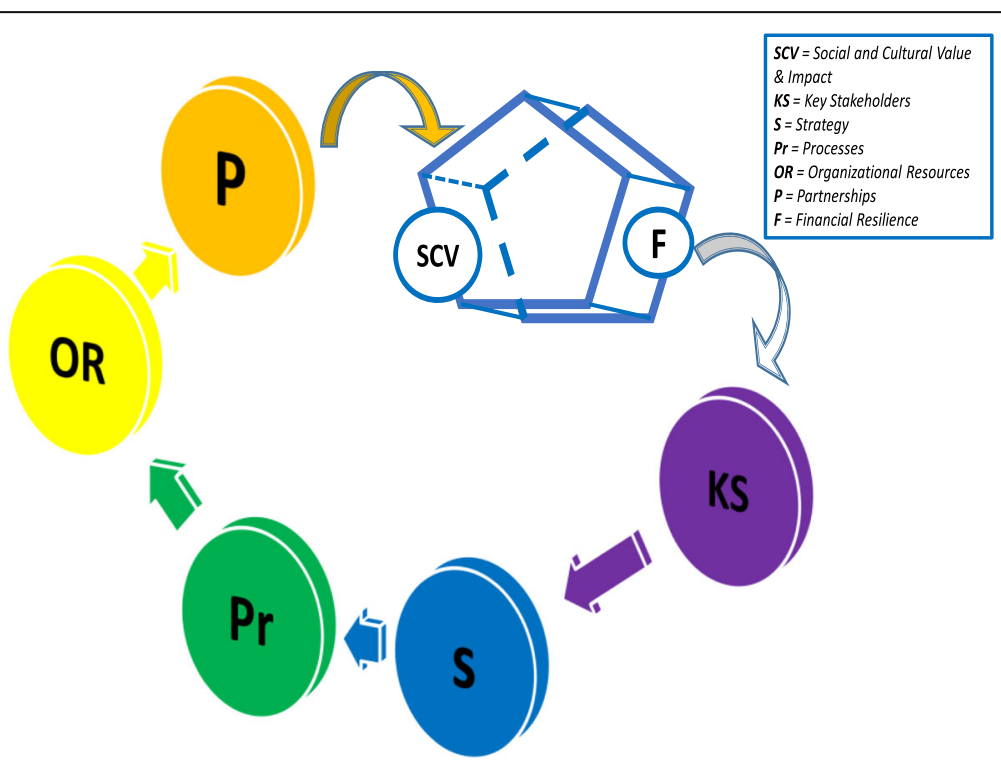

Fig. 3 Implementing the Business Model Prism 
development, both at industrial and societal level. For this reason, it is of great relevance to understand how the arts and cultural organisations can manage and innovate their business models towards the capacity of shaping strategies and operations that can make them more sustainable and impactful.

The traditional models and tools devised to support public and private organisations to analyse and develop their business models, even if provide useful insights for the cultural sector, present limitations when applied to the arts and cultural organisations due to the specific characteristics of those organisations. In order to effectively balance the tension between the social and cultural values and the commercial values, the arts and cultural organisations need to design and apply business models, also in an implicit form, capable to identify and address their specific value propositions, resources requirements, activities delivering and economic and financial structures.

In order to fill the gap in the literature a novel framework is proposed: the Business Model Prism aims to support the mapping of a current business model as well to inspire and drive its transformation.

Future development of the research reside both at theoretical and empirical level. From conceptual point of view the hypothesis at the basis of the model need to be further developed in order to improve the granularity level of the different framework's dimensions. From empirical standpoint the model need to be tested into real cases both by action research projects and by developing surveys aimed at identifying the key traits of business model innovations of the arts and cultural organisations.

Acknowledgements

Not applicable

\section{Funding}

This paper collects and presents some insights of the research develop alongside the project "Creative Lenses" Cooperation Agreement "Creative Lenses" - Creative Europe 2014, Cultural Sub Programme, European Cooperation Project - Cat. 2 Large managed by EACEA - Agreement number: 2015-1141/001-002.

\section{Authors' contributions}

The individual contributions of authors to the manuscript: GS: The role of business model innovation for the arts and cultural organizations and The Business Model Prism sections. AL: Introduction, Background and Conclusions sections. Both authors read and approved the final manuscript.

\section{Competing interests}

The authors declare that they have no competing interests.

\section{Publisher's Note}

Springer Nature remains neutral with regard to jurisdictional claims in published maps and institutional affiliations.

Received: 14 July 2017 Accepted: 10 August 2017

Published online: 30 August 2017

\section{References}

Afuah, A., \& Tucci, C. L. (2003). A model of the internet as creative destroyer. IEEE Transactions on Engineering Management, 50(4), 395-402.

Amit, R., \& Zott, C. (2001). Value creation in e-business. Strategic Management Journal, 22(6-7), 493-520.

Arts Council England (2011) Business Models in the Visual Arts (author: S.J. Royce). UK: Arts Council England publication. ISBN: 978-0-7287-1499-1.

Baden-Fuller, C., \& Haefliger, S. (2013). Business models and technological innovation. Long Range Planning, 46, 419-426.

Bollo, A. (2013). 50 sfumature di pubblico e la sfida dell'audience development. Torino: Fondazione Fitzcarraldo.

Casadesus-Masanell, R., \& Ricart, J.E. (2007). Competing through business models. IESE Business School Working paper No. 713.

Casadesus-Masanell, R., \& Zhu, F. (2013). Business model innovation and competitive imitation: The case of sponsorbased business models. Strategic Management Journal, 34(4), 464-482.

Chesbrough, H., \& Rosenbloom, R. (2002). The role of business model in capturing value from innovation. Evidence from Xerox Corporation's technology spin-off companies. Industrial and Corporate Change, 11(3), 529-555. 
Cohen, B. \& Winn, M.I. (2007). Market imperfections, opportunity and sustainable entrepreneurship. Journal of Business Venturing, 22(2), pp. 29-49.

Cunningham, S. (2002). From cultural to creative industries: Theory, industry and policy implications. Media International Australia incorporating Culture and Policy, 102(1), 54-65.

DaSilva, C. M., \& Trkman, P. (2014). Business model: What it is and what it is not. Long Range Planning, 47, 379-389.

Downing, S. (2005). The Social Construction of Entrepreneurship: Narrative and Dramatic Processes in the Coproduction of Organizations and Identities. Entrepreneurship Theory and Practice, 29(2), pp. 185-204.

Enev, V. and Liao, W.C. (2014) Business model innovation and factors influencing business model innovation, Master Corporate Entrepreneurship and Innovation, Department of Business Administration. Lund: Lund University Libraries.

Frankenberger, K., Weiblen, T., Csik, M., \& Gassmann, O. (2013). The 4l-framework of business model innovation: A structured view on process phases and challenges. International Journal of Product Development, 18(3-4), 249-273.

George, G., \& Bock, A. J. (2011). The business model in practice and its implications for entrepreneurship research. Entrepreneurship Theory and Practice, 35(1), 83-111.

Girotra, K., \& Netessine, S. (2013). Om forum-business model innovation for sustainability. Manufacturing \& Service Operations Management, 15(4), 537-544.

Girotra, K., \& Netessine, S. (2014). Four paths to business model innovation. Harvard Business Review, 92(7), 96-103.

Hedman, J., \& Kalling, T. (2002). IT and business models. Malmö: Liber/Abstrakt.

Helmig, B., Jegers, M., \& Lapsley, I. (2004). Challenges in management of nonprofit organizations: A research overview. Volunteers: International Journal of Voluntary and Nonprofit Organizations, 15, 101-116.

Hume, M., Sullivan Mort, G., Liesch, P. W., \& Hume, W. (2006). Understanding service experience in non-profit performing arts: Implications for operations and service management. Journal of Operations Management, 24, 304-324.

IDEA Consult (2013). Survey on access to finance for cultural and creative sectors: Evaluate the financial gap of different cultural and creative sectors to support the impact assessment of the creative Europe programme.

Kaplan, S. (2011). Business models aren't just for business. Harvard Business Review.

Kaplan, R. S., \& Norton, D. P. (1996). The balanced scorecard: Translating strategy into action. Boston: Harvard Business Press.

Kaplan, R. S., \& Norton, D. P. (2000). Having trouble with your strategy? Then map it! Harvard Business Review, 78(5), 167-176.

KEA (2006). The Economy of culture in Europe - http://www.keanet.eu/studies-and-contributions/economy-of-culturein-europe/. Accessed 20 May 2017.

Linder, J., \& Cantrell, S. (2000). Carved in Water: Changing Business Models fluidly. Accenture Institute for Strategic Change Research Report, pp. 8-10.

Lindgren, P., \& Rasmussen, R. (2012). Business model innovation leadership. Journal of Multi Business Model Innovation and Technology, 1(1), 53-69.

MacMillan, I.C. (1989). Delineating a forum for business policy scholars. Strategic Management Journal, 10(4), pp. 391-395.

MacMillan, I.C. (1991). Delineating a forum for business policy scholars. Strategic Management Journal, 12(2), pp. 161-165.

MacMillan, I.C. (1994). Delineating a forum for business policy scholars. Journal of Business Venturing, 9(2), pp. 85-89.

MacMillan, I.C. \& Stern, I. (1987). Delineating a forum for business policy scholars. Strategic Management Journal, 8(2), pp. 183-186.

Magretta, J. (2002). Why business models matter. Harvard Business Review, 80(5), 86-92.

Markides, C. (2006). Disruptive innovation: in need of better theory. Journal of Product Innovation Management, 23(1), pp. 19-25.

Markides, C. C. (2013). Business model innovation: What can the ambidexterity literature teach us? The Academy of Management Perspectives, 27(4), 313-323.

Maurya, A. (2012) Running Lean. Create from Plan A to a Plan that works, O'Reilly, Sebastopol, USA.

Munoz-Seca, B. (2011). A business model for cultural services. Joint design and production of a customer experience, IESE Business School Working Paper WP- 941

Munoz-Seca, B., \& Riverola, J. (2008). The new operational culture: The case of the theatre industry. London: Palgrave.

Munoz-Seca, B., \& Riverola, J. (2010). When Business Meets Culture. London: Palgrave.

Neely, A. (2002). Business performance measurement: Theory and practice. Cambridge: Cambridge University Press.

Neely, A., \& Adams, C. (2001). The performance prism perspective. Journal of Cost Management, 15(1), 7-15.

Neely, A., Adams, C., \& Crowe, P. (2001). The performance prism in practice. Measuring Business Excellence, 5(2), 6-13.

Neely, A., Adams, C., \& Kennerley, M. (2002). The performance prism: The scorecard for measuring and managing business success. London: Financial Times-Prentice Hall.

Nesta (2014). The new art of finance - Making money work harder for the arts, London: Nesta.

Nesta (2015). Digital Culture: How arts and cultural organizations in England use technology, London: Nesta.

Osterwalder, A.s \& Pigneur, Y. (2010). Business model generation: A handbook for visionaries, game changers, and challengers. London: Wiley.

Ostrower, F. (2004). Partnerships between large and small cultural organizations. Washington DC: The Urban Institute.

Schiuma, G. (2011). The value of arts for business. Cambridge: Cambridge University Press.

Schiuma, G., \& Lerro, A. (2013). Fostering innovation through collaboration between cultural and creative industries and traditional business sectors. Report presented at Creative Capital Conference "Fostering cross-innovation, 4th November, Vigevano, Italy.

Schiuma, G., \& Lerro, A. (2014). Do cultural and creative industries (CCI) matter for innovation and value creation in knowledge-based business? Aims, forms and practices of collaboration in Italy. Istanbul: Knowledge Cities World Summit.

Schneider, S., \& Spieth, P. (2013). Business model innovation: Towards an integrated future research agenda. International Journal of Innovation Management, 17(1), 1340001.

Smagina, A., \& Lindemanis, A. (2012). What creative industries have to offer to business? Creative partnerships and mutual benefits. World Academy of Science, Engineering and Technology, 71, 1839-1844.

Spieth, P., Schneckenberg, D., \& Ricart, J. E. (2014). Business model innovation-state of the art and future challenges for the field. R\&D Management, 44(3), 237-247.

Teece, D. J. (2010). Business models, business strategy and innovation. Long Range Planning, 43(2), 172-194.

TEH - Trans Europe Halles (2015) Schiuma, A., Bogen, P., Lerro, A., eds. Creative business models: Insights into the business models of cultural centers in trans Europe Halles, City of Lund - Creative Plot and Trans Europe Halles, Lund, Sweden. 
Thorsby, D. (2008) From Cultural to Creative Industries: the Specific Characteristics of the Creative Industries, paper presented at Troiseime Journees d'Economie de la Culture: Nouvelles Frontieres de l'Economie de la Culture, Paris, 2-3 October.

Tikkanen, H., Lamberg, J. A., Parvinen, P., \& Kallunki, J. P. (2005). Managerial cognition, action and the business model of the firm. Management Decision, 43(6), 789-809.

Timmers, P. (1998). Business models for electronic markets. Electronic Markets, 8(2), 3-8.

United Nations. (2008). Creative Economy Report 2008, UNCTAD secretariat and UNDP special unit for south-south. Geneva and New York: Cooperation.

Wirtz, B.W. (2000). Electronic Business. London: Springer-Verlag

Wirtz, B. W. (2001). Electronic business. London: Springer-Verlag.

Wirtz, B. W. (2010). Business model management. Gabler: Wiesbaden.

Wirtz, B.W. (2011). Business Model Management. Design-Instruments-Success Factors. Gabler: Wiesbaden.

Wirtz, B. W., Pistoia, A., Ulrich, S., \& Gottel, V. (2016). Business models: Origins, development and future research. Long Range Planning, 49, 36-54.

Zomerdijk, L. G., \& Voss, C. A. (2010). Service design for experience-centric services. Journal of Service Research, 13(1), 67-82.

Zott, C., \& Amit, R. (2008). Business Model Innovation: Creating Value in Times of Change. IESE Business School Working Paper No. 870

Zott, C., Amit, R., \& Massa, L. (2011). The business model: Recent developments and future research. Journal of Management, 37(4), 1019-1042.

Submit your manuscript to a SpringerOpen ${ }^{\circ}$ journal and benefit from:

- Convenient online submission

- Rigorous peer review

- Open access: articles freely available online

- High visibility within the field

- Retaining the copyright to your article

Submit your next manuscript at $>$ springeropen.com 